Materials Sciences Division, Lawrence Berkeley National Laboratory, and Department of Materials Science and Engineering, University of California at Berkeley

\title{
PROTECTIVE COATING ON STAINLESS STEEL INTERCONNECT FOR SOFCs: OXIDATION KINETICS AND ELECTRICAL PROPERTIES
}

\author{
${ }^{1}$ X. Chen, ${ }^{1}$ P.Y. Hou, ${ }^{1}$ C.P. Jacobson, ${ }^{1}$ S.J. Visco, and L.C. De Jonghe ${ }^{1,2}$ \\ ${ }^{1}$ Materials Science Division, Lawrence Berkeley National Laboratory, and \\ Department of Materials Science and Engineering \\ University of California, Berkeley, CA 94720, USA \\ ${ }^{1,2}$ Corresponding author: \\ Department of Materials Science and Engineering \\ 324 Hearst Mining Building, \\ University of California, Berkeley, CA 94720-1760 \\ Tel: (510) 486-6139; Fax: (510) 486-4881 \\ E-mail address: LCDejonghe@lbl.gov (L.C. De Jonghe)
}

submitted May 2004

Solid State Ionics

Work supported by the Director, Office of Science, Office of Basic Energy Sciences, Division of Materials Sciences and Engineering of the U.S. Department of Energy under Contract No. DEAC03-76SF00098. 


\title{
PROTECTIVE COATING ON STAINLESS STEEL INTERCONNECT FOR SOFCs: OXIDATION KINETICS AND ELECTRICAL PROPERTIES
}

\author{
X. Chen, P.Y. Hou, C.P. Jacobson, S.J. Visco, and L.C. De Jonghe \\ Materials Sciences Division, Lawrence Berkeley National Laboratory, and \\ Department of Materials Science and Engineering, University of California, Berkeley, CA 94720
}

\begin{abstract}
An effective, dense and well adherent coating was produced on 430SS that has the result of significantly reducing the oxidation rate of this alloy at elevated temperatures. The coating is essentially a Mn-Co-O spinel, applied in powder form, and compacted to improve its green density. A simplified model is presented that allows an assessment of the effects of the contact and scale geometries. For $850^{\circ} \mathrm{C}$, an ASR can be predicted of approximately $0.5 \Omega \mathrm{cm}^{2}$, after $50,000 \mathrm{hrs}$ in air, taking into account a factor of 10 penalty for unfavorable contact geometries. The effect of the densified Mn-Co spinel coating is to reduce significantly $\mathrm{Cr}_{2} \mathrm{O}_{3}$ sub-scale formation, lower the thermal expansion mismatch, and increase the electronic conductivity of the scale.

The findings point to several potential remedies for achieving coatings on $430 \mathrm{SS}$ that allow for metal interconnects with a service life of 50,000hrs or more. Considering contact geometries, such service life is unlikely to be possible above operating temperatures of about $700^{\circ} \mathrm{C}$, unless highly specialized alloys are used, with potential processing and cost penalties.
\end{abstract}

Keywords: Interconnect, Stainless steel, $\mathrm{Cr}_{2} \mathrm{O}_{3}$, SOFC, ASR

\footnotetext{
${ }^{*}$ Corresponding author. Tel: +1-510-486-6138; fax: +1-510-486-4881. E-mail address: lcdejonghe@lbl.gov (L.C. DeJonghe) ${ }^{\dagger}$ Supported by the Director, Office of Science, Office of Basic Energy Sciences, Division of Materials Sciences and Engineering of the U.S. Department of Energy under Contract No. DE-AC03-76SF00098.
} 


\section{Introduction}

Interconnects in solid oxide fuel cells (SOFCs) provide the electrical connection between the individual cells, as well as separate the anode form the cathode compartments. To properly function in SOFCs, the interconnect materials must possess a combination of physical and electrical properties:

1) High temperature oxidation resistance in both anode and cathode atmospheres

2) High electrical conductivity and negligible ionic conductivity

3) Thermal expansion compatibility with the other parts of the SOFC

4) Zero open porosity and sufficient mechanical strength

5) Chemical compatibility with the materials it contacts

6) Thermodynamic stability over the applied temperature range

Recently, significant progress has been made toward intermediate-temperature SOFCs $\left(\sim 800^{\circ} \mathrm{C}\right)$, which can keep the cell power density and durability at the same level as those high temperature SOFCs. This progress is achieved by reducing the thickness of the conventional doped zirconia electrolytes [1-3] and/or by the development of new electrolytes with better oxide-ion conductivity than the traditional yttria stabilized zirconia (YSZ) [4-6]. At about $800^{\circ} \mathrm{C}$, high temperature oxidation-resistant ferritic steels are considered to be the most promising interconnect materials. Among these alloys, chromium based alloys [7-9] are mostly studied because they have a number of advantages: (1) The coefficient of thermal expansion, CTE, of ferritic Cr-based alloys is close to that of other cell components. For example, the CTEs of a LSM (lanthanum strontium manganate) and a $430 \mathrm{Fe}-\mathrm{Cr}$ alloy are $11-13 \times 10^{-6}$ and $9-12 \times 10^{-6} \mathrm{~K}^{-1}$, respectively [10]. (2) Cr-based alloys, especially stainless steels such as the 430 or 446 ferritic alloys, are low cost and have excellent machinability. However, particularly in oxidizing 
atmospheres, the formation of chromia scales leads to high contact resistances deleterious to the fuel cell performance. In addition, volatile $\mathrm{Cr}$ species can be released from the $\mathrm{Cr}_{2} \mathrm{O}_{3}$ scale, depending on the temperature and partial pressures of $\mathrm{H}_{2} \mathrm{O}$ and $\mathrm{O}_{2}$ [11]. The presence of the volatile chromium species, notably $\mathrm{CrO}_{2}(\mathrm{OH})_{2}$, in the cathode of an SOFC is known to cause rapid cathode poisoning and performance degradation.[12] Improving the electrical properties of the oxide layer that forms on a metallic interconnect requires suppressing the formation of the resistive $\mathrm{Cr}_{2} \mathrm{O}_{3}$ phase, and promoting the formation of more conductive phases. Further, the transport of $\mathrm{Cr}$ to the gas-phase must be inhibited by a dense protective coating. The effectiveness of the coating must be maintained for very extended periods, e.g. 50,000hrs or more [13].

In the present work, a dense Mn-Co containing surface oxide coating is reported that was produced on a commercial 430 stainless steel, forming an electronically highly conductive, protective spinel, and involving solid-state reaction with $\mathrm{Cr}_{2} \mathrm{O}_{3}$ during oxidation of the steel. Solid-state reaction can be an economical process compared to plasma spraying or chemical vapor deposition. Previous studies by Huang et al. [14], indicated that the electronic conductivity of $\mathrm{Cr}_{2} \mathrm{O}_{3}$ can be improved by the incorporating and $\mathrm{Co}$ and $\mathrm{Mn}$, as would result from the reaction with a Co-Mn oxide coating.

Quadakkers et al. [15] showed that a Mn-Cr-O spinel phase instead of $\mathrm{Cr}_{2} \mathrm{O}_{3}$ was formed as the contact layer between LSM cathode and the Cr-based alloy interconnect during oxidation due to solid-state and gas phase transport of chromium species. This transport led to the formation of a $\mathrm{CoCr}_{2} \mathrm{O}_{4}$ spinel when the coating was $\mathrm{LaCoO}_{3}$, and to the formation of $\mathrm{MnCr}_{2} \mathrm{O}_{4}$ when the contacting material was LSM. The formation of this spinel near the interface with the Cr-based alloy can produce a local enrichment of $\mathrm{La}$ in the middle of the coating. As a result, $\mathrm{La}_{2} \mathrm{O}_{3}$ that is formed may hydrolyze in water containing atmospheres, leading to mechanical degradation of the coating. Early investigations by Wickham and Croft [15] and by Naka et al. [16] have shown that Mn-Co-O spinel has a high electronic conductivity, and could be a useful 
electrode in a number of electrochemical devices. The high electronic conductivity follows when mixed valence ions are present on the same spinel sublattice, facilitating electron transport. Larring and Norby [17] reported that a Mn-Co-O spinel was able to reduce Cr interdiffusion significantly between a Plansee alloy and a contacting LSM/LSC (lanthanum strontium manganate/ lanthanum strontium cobaltate) mixed perovskite when it was introduced as an interlayer, also leading to an ASR (area specific resistance) of the metal/ceramic interface of only 0.024 ohmcm ${ }^{2}$ after 10,000 hours at $\sim 950^{\circ} \mathrm{C}$, in air. Badwal, et al. in a recent patent [18] reported oxide coatings containing at least one metal, $\mathrm{M}$, selected from the transition series $\mathrm{Mn}$, Fe, Co and Ni. An M-Cr spinel layer would develop between the metal substrate and the coating layer by the reaction of the oxide with the surface chromium oxide that forms on the alloy substrate.

The present work considers further the use of a Mn-Co-O spinel coating on a 430 stainless steel, forming a protective layer that slows the chromia scale formation significantly while maintaining a low interface resistance, and it examines its behavior under thermal cycling, and comments on the role of contact geometry. Possible mechanisms involved in the modifications to the oxidation kinetics are also discussed.

\section{Experimental}

\subsection{Spinel coating powder preparation}

$\mathrm{MnCr}_{2} \mathrm{O}_{4}, \mathrm{Mn}_{1.5} \mathrm{Cr}_{1.5} \mathrm{O}_{4}, \mathrm{MnCrCoO}_{4}$, and $\mathrm{MnCo}_{2} \mathrm{O}_{4}$ were prepared by a glycine nitrate combustion synthesis [19]. The molar ratio of glycine-to-metal ions was 2:1. After combustion, the spinel powder was calcined at $1100^{\circ} \mathrm{C}$ in air, for 2 hours, to remove residual carbon. The powder was attritor-milled in isopropanol, for 1 hour, at $550 \mathrm{rpm}$. The various materials were compacted and sintered into pellets suitable for thermal expansion measurements by dilatometry and for electrical measurements. 


\subsection{Electrical properties determination}

After drying, the attritor-milled spinel powders were compacted into pellets in a $2 \mathrm{~cm}$ diameter steel die, at about $70 \mathrm{MPa}$. The pellets were sintered at $1300^{\circ} \mathrm{C} / 4 \mathrm{~h}$ in air, and their conductivities were determined every $50^{\circ} \mathrm{C}$ by a four-probe method, similar to the one used by Huang et al. [14], but using gold rather than platinum paste. The results of the measurements, together with literature data on $\mathrm{Cr}_{2} \mathrm{O}_{3}$ conductivities [20], are shown in Fig. 1. The manganese cobalt spinel showed the highest electronic conductivity. $\mathrm{Cr}_{2} \mathrm{O}_{3}$ generally has a much lower electronic conductivity. Increasing the $\mathrm{Cr}$ contents of the spinel correlates with decreasing electronic conductivities for this spinel. This indicates that reaction of $\mathrm{MnCo}_{2} \mathrm{O}_{4}$ with $\mathrm{Cr}_{2} \mathrm{O}_{3}$ could be expected to lead to scales of improved conductivity. The $\mathrm{MnCo}_{2} \mathrm{O}_{4}$ spinel was therefore selected as the most promising coating material.

\subsection{Coating method and oxidation heat treatments}

A commercial ferritic 430 stainless steel $(150 \mu m$ thick) was selected for this study, because of its low cost, ready availability, and suitable chromium content. The composition, provided by the supplier, is shown in Table 1 . The steel sheets were cut into $1 \mathrm{cmx} 1 \mathrm{~cm}$ square samples, and abraded on both sides with \#1200 grit SiC sandpaper. A slurry was prepared by dispersing the attritor-milled spinel powders in IPA (isoproponal) together with 5wt\% HPC (Hydroxypropyl cellulose). A strongly adherent coating could be produced by slurry-spraying the prepared steel surfaces, using an Iwata Eclipse HP-BCS spray gun. The as-deposited coatings were approximately $15-20 \mu \mathrm{m}$ thick. To evaluate the effects of the green density of the coating, some coated samples were mechanically compressed to $70 \mathrm{MPa}$ prior to heating. 
Three types of samples were prepared,

Sample type A: Uncoated 430 stainless steel

Sample type B. 430 stainless steel coated with $\mathrm{MnCo}_{2} \mathrm{O}_{4}$

Sample type C: 430 stainless steel, coated with $\mathrm{MnCo}_{2} \mathrm{O}_{4}$ and mechanically compacted

The samples were heated first at $800^{\circ} \mathrm{C}$ for an initial oxidation, for $60 \mathrm{hrs,} \mathrm{in} \mathrm{stagnant} \mathrm{air.}$ This treatment served to densify the sprayed-on coating, and to form an initial $\mathrm{Cr}_{2} \mathrm{O}_{3}$ scale. Following this initial oxidation, the samples were either held at $850^{\circ} \mathrm{C}$ in air, or subjected to cyclic oxidation between room temperature and $850{ }^{\circ} \mathrm{C}$ with 30 min holds at temperature, to an additional cumulative exposure at $850^{\circ} \mathrm{C}$ of 120 hrs. Heating and cooling rates were approximately $20^{\circ} \mathrm{C} / \mathrm{min}$. Cyclic oxidation should be expected to lead to spalling and delamination of the scales if there are significant thermal expansion mismatches between the scale and the substrate alloy, particularly for thick coatings.

\section{Results and discussions}

\subsection{Thermal expansion measurements.}

The results of the differential thermal expansion measurements, with LSM as a reference, are listed in Table 2. The CTE of $\mathrm{MnCo}_{2} \mathrm{O}_{4}$ is nearly identical to that of LSM, while the incorporation of $\mathrm{Co}$ in $(\mathrm{Mn}, \mathrm{Cr})_{3} \mathrm{O}_{4}$ spinels significantly reduces the $\triangle \mathrm{CTE}$ with LSM or $430 \mathrm{SS}$. A low $\triangle \mathrm{CTE}$ is essential for forming scales that can adhere up to some large critical thickness.

\subsection{Effects of coating compaction}

Cross-sectional SEM (scanning electron microscope) images of Sample B and Sample C after the single initial oxidation in air at $800^{\circ} \mathrm{C}$, for $60 \mathrm{hrs}$, are compared in Fig. 2a and $2 \mathrm{~b}$. It is evident that the compaction of the as-deposited coating improved the density of the coating layer very significantly. Without this compaction, the as-deposited Mn-Co-O spray coating remains porous, providing poor protection. Therefore, the density of the deposited coating prior to firing 
needs to be high, as may be achieved either by mechanical compaction or by alternative deposition processes such as electrophoresis. In this work, other coating application methods were not examined, and only mechanical compaction was pursued.

\subsection{Oxidation Kinetics and cyclic oxidation}

Samples of type A and C, after the initial oxidation, were suspended in a Cahn microbalance, in stagnant air, for 120 hrs, and weight gains were recorded over time after a constant temperature of $850^{\circ} \mathrm{C}$ was reached. A second set of samples, after the initial oxidation at $800^{\circ} \mathrm{C}$, was subjected to cyclic oxidation between room temperature and $850^{\circ} \mathrm{C}$, with dwell times of approximately $30 \mathrm{~min}$ up to a cumulative exposure of $120 \mathrm{hrs}$ at $850^{\circ} \mathrm{C}$, and weight changes were recorded at room temperature every 2-5 cycles. Cooling/heating rates were approximately $20^{\circ} \mathrm{C} / \mathrm{min}$. The oxidation results are shown in Fig. 3. Weight gain for the coated steel is reduced very significantly compared to the uncoated steel. Weight gain for the uncoated steel in cyclic oxidation was apparently low, but this was due to the extensive spalling of the oxide coating, and does not represent improved oxidation resistance. In contrast, the scale formed on the coated/compacted samples did not show any evidence of spalling, and remained fully adherent throughout the cyclic oxidation. The weight gain of the uncoated steel, sample type A, during the $850^{\circ} \mathrm{C}$ oxidation, and of the coated/compacted samples (type C) during cyclic oxidation, could be fitted to a near parabolic relationship with time. This is expected when the oxide scale growth is controlled by diffusion of ions through a dense scale. A rate constant, $\mathrm{k}_{\mathrm{g}}$, given in Table 3, characterizing the rate of weight gain, $d \Delta \mathrm{W} / d \mathrm{t}$, as a result of oxidation can be

defined by $(\Delta \mathrm{W})^{2}=\mathrm{kg}_{\mathrm{g}}$. The scale structure in the present case is complex and, as a result, a corresponding simple parabolic rate constant for the thickness increase can not be readily defined. For comparison of the different oxidation rates obtained by others, however, an effective

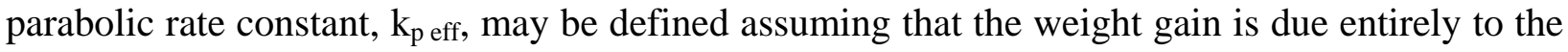
formation of a dense $\mathrm{Cr}_{2} \mathrm{O}_{3}$ layer, although part of this chromia scale will react with the coating. 
With this assumption, and $k_{p, \text { eff }}$ in $\mu \mathrm{m} / \sqrt{ }_{\text {hour, }} k_{p, \text { eff }}$ is defined by [14]:

$\mathrm{k}_{\mathrm{p} \text { eff }}=6 \cdot 10^{5}\left(\frac{\mathrm{MW}_{\mathrm{Cr}_{2} \mathrm{O}_{3}}}{(3 / 2) \mathrm{MW}_{\mathrm{O}_{2}}} \cdot \frac{1}{\rho_{\mathrm{Cr}_{2} \mathrm{O}_{3}}}\right) \sqrt{ } \mathrm{kg}_{\mathrm{g}}$.

where $\mathrm{MW}_{\mathrm{Cr}_{2} \mathrm{O}_{3}}$ and $\mathrm{MW}_{\mathrm{O}_{3}}$ are the molecular weights of chromia and oxygen, and $\rho_{\mathrm{Cr}_{2} \mathrm{O}_{3}}$ is the density of chromia $\left(5.21 \mathrm{~g} / \mathrm{cm}^{3}\right)$, so that an approximate effective chromia scale thickness, $\mathrm{X} \mathrm{Cr}_{2} \mathrm{O}_{3}$ can be obtained from $X \mathrm{Cr}_{2} \mathrm{O}_{3}=k_{p, \text { eff }} \cdot \sqrt{t}$. These rate constants, Table 3, show that at $850^{\circ} \mathrm{C}$, the coated/compacted steel, sample type $\mathrm{C}$, has a substantially reduced oxidation rate compared to the uncoated steel, sample type A. Extrapolation to a 50,000 hr exposure at $850^{\circ} \mathrm{C}$, with $\mathrm{k}_{\mathrm{p} \text { eff }}=4.4 \times 10^{-2} \mu \mathrm{m} / \sqrt{ }$ hour would lead to an effective chromia scale thickness of about $10 \mu \mathrm{m}$, compared to over $100 \mu \mathrm{m}$ for the unprotected steel (provided this scale would not spall off or be limited by Cr evaporation). The values of $\mathrm{k}_{\mathrm{p} \text { eff }}$ for the cyclic oxidation appear to be slightly higher because the heating and cooling periods are not accounted for. These results may be compared to the reduced oxidation rates reported by Zhu et al. [21] for a 444 stainless steel coated with a thin layer of $\mathrm{LaCrO}_{3}$, involving r.f. sputtering and reaction or sol-gel coating, giving a $\mathrm{k}_{\mathrm{g}}$ of about $5.8 \times 10^{-14} \mathrm{~g}^{2} \mathrm{~cm}^{-4} \mathrm{~s}^{-1}$ or a $\mathrm{k}_{\mathrm{p} \text { eff }}=8.7 \times 10^{-2} \mu \mathrm{m} / \widehat{ }_{\text {hour }}$ at $800^{\circ} \mathrm{C}$, corresponding to a $50,000 \mathrm{hr}-800^{\circ} \mathrm{C}$ projected effective chromia scale thickness of about $20 \mu \mathrm{m}$. Huang et al. [14] reported that for an Ebrite alloy with an yttrium reactive element coating $\mathrm{k}_{\mathrm{p} \text { eff }}$ at $800^{\circ} \mathrm{C}$ was $4 \times 10^{-2} \mu \mathrm{m} / \sqrt{ }$ hour. For a $50,000 \mathrm{hr}$ exposure at $800^{\circ} \mathrm{C}$, this would also lead to a little more than an $\sim 10 \mu \mathrm{m}$ effective scale thickness of $\mathrm{Cr}_{2} \mathrm{O}_{3}$. Thick scales are very likely to spall off, as the oxidation of the uncoated steel shows. An additional requirement for the coating and the scale that it forms on oxidation is that the area specific contact resistance (ASR), has to remain within acceptable limits. 


\subsection{Scale microstructures}

Optical microscopy (KEYENCE VH-Z450 optical microscope) of the surfaces of the uncoated steel, Sample type A, after a $120 \mathrm{hr}$ cyclic oxidation at $850^{\circ} \mathrm{C}$ clearly showed extensive spalling of the scale, Fig.4a; the apparently low oxidation rate of the unprotected steel (sample type A- Fig 2 ) is therefore the result of repeated spalling/reoxidation events, in which scale regrowth starts again after the scale is removed. Scale spalling was almost complete upon cooling sample type A once to room temperature after a $120 \mathrm{hr}$ isothermal oxidation at $850^{\circ} \mathrm{C}$, due to the formation of much thicker scale, Fig $4 \mathrm{~b}$. However, for oxidations at $800^{\circ} \mathrm{C}$ up to $180 \mathrm{hrs}$, the scale was retained for sample type A (not coated), so that meaningful resistivity measurements could be made.

Cross sectional chemical analyses of the scale compositions were carried out in a ISI DI30C scanning electron microscope equipped with an EDX (energy dispersing X-ray) analytical system. To avoid electrical charging, all samples were coated with Au-Pd alloy in a Pelco Model 3 sputtering coater.

The results for a Type A sample (no coating) oxidized for $60 \mathrm{hrs}$ at $800^{\circ} \mathrm{C}+120$ hrs isothermally at $850^{\circ} \mathrm{C}$, and for a Type C sample (coated-compacted) after 60 hrs at $800^{\circ} \mathrm{C}+\mathrm{a}$ cumulative cyclic oxidation of $120 \mathrm{hrs}$ at $850^{\circ} \mathrm{C}$, are shown in Figs. 5a and b, respectively. The chemical analysis for Fig 5a was obtained from a fragment of the rough scale that still adhered. The oxide layer for sample Type A is about $5 \mu \mathrm{m}$ thick, and consists of a chromia sub-scale under an outer manganese-chromia spinel layer. The manganese in this case came from the 430 SS alloy itself, due to its high mobility and high oxidation potential. Formation of a $(\mathrm{Mn}, \mathrm{Cr})_{3} \mathrm{O}_{4}$ spinel in contact with a manganese-containing $\mathrm{Cr}_{2} \mathrm{O}_{3}$ scale is in agreement with the known phase relationships at this temperature, as determined by Speidel and Muan [22], where the Mn-Cr stability field extends to a $\sim 40 / 60 \mathrm{Mn} / \mathrm{Cr}$ composition in air. The chromia subscale on the coated alloy (sample type C) oxidized at $850{ }^{\circ} \mathrm{C}$, Fig. $6 \mathrm{~b}$ is only of submicron thickness; the exact 
thickness cannot be determined accurately form the EDX traces, due to the convolution of the compositional measurements resulting form the finite width of the electron beam probe $(\sim 1 \mu \mathrm{m}$ in diameter). The EDX line scans indicate that Cr has been incorporated to some extent into the coating, but at a concentration significantly lower than for $\mathrm{Cr}_{2} \mathrm{O}_{3}$. This suggests that $\mathrm{Cr}$ evaporation may be expected to be strongly reduced as well, but direct measurements of $\mathrm{Cr}$ loss remain to be made.

\subsection{Areas Specific Resistances (ASRs)}

The electrical resistances of sample type C (coated), after thermal cycling, and Sample A ( uncoated 430SS) held isothermally at $800^{\circ} \mathrm{C}$ for 180 hours in air, were measured every $50^{\circ} \mathrm{C}$ from about $600^{\circ} \mathrm{C}$ to $800^{\circ} \mathrm{C}$ by the four-probe method. The results are shown in Fig. 6. Apparent activation energies for the ASRs, $E_{\mathrm{a}, \mathrm{el}}(\mathrm{eV})$, were obtained by fitting to an Arrhenius expression: $\operatorname{ASR}\left(\Omega \mathrm{cm}^{2}\right)=(\mathrm{B} \cdot \mathrm{T}) \cdot \exp \left(E_{\mathrm{a}, \mathrm{e}} / \mathrm{kT}\right)$, where $\mathrm{T}$ is the temperature, $\mathrm{k}$ is the Boltzmann constant, and $\mathrm{B}\left(\Omega \mathrm{cm}^{2} \mathrm{~K}^{-1}\right)$ is a constant. The ASRs decrease with increasing temperatures because the scales are n-type semiconductors. The temperature dependence of the ASR can be characterized by activation energies generally between 0.85 and about $1 \mathrm{eV}$. It is intriguing that the ASRs of the samples, with the exception of the uncoated steel oxidized for 180 hrs at $800^{\circ} \mathrm{C}$, are clustered around the same values.

The ASRs of the uncoated 430SS fired at $800^{\circ} \mathrm{C}$ for 180 hours are about one order of magnitude higher than those of the coated samples, Fig.7. The ASR for the coated sample, initially oxidized for 60 hrs at $800^{\circ} \mathrm{C}$, followed by an additional cyclic oxidation at $850^{\circ} \mathrm{C}$ for 120 hrs, is as low as $2.5 \times 10^{-3} \mathrm{ohmcm}^{2}$. This is the lowest value obtained so far for a coated $430 \mathrm{SS}$ at $850^{\circ} \mathrm{C}$, particularly under similar thermal cycling conditions. 


\subsection{Mechanisms}

The oxidation rate measurements and EDX data suggest plausible mechanisms for the oxidation of the coated and the uncoated samples. For the unprotected steel, during the initial oxidation Mn in the alloy is preferentially oxidized, leading to the formation a Mn-Cr spinel surface layer that is not protective, and continued oxidation forms a Mn-containing $\mathrm{Cr}_{2} \mathrm{O}_{3}$ scale that grows essentially unimpeded. For the coated steel, the dense Mn-Co-O layer has several beneficial effects: it eliminates the oxidation of $\mathrm{Mn}$ in the alloy, since the oxygen potential at the coating/alloy interface is effectively lowered; it significantly reduces the chromia subscale growth by blocking oxygen ingress; it improves the overall coating adherence, probably due to the formation of a thinner and more compact $\mathrm{Cr}_{2} \mathrm{O}_{3}$ scale; it introduces $\mathrm{Co}$ in the overall oxide layer on the alloy surface, which has the effect of significantly increasing its electronic conductivity, as well as lowering the thermal expansion to values more compatible with that of the steel.

\subsection{ASR, contact geometry, and scale thickness}

Simplified models can be used to estimate the effects of partial contact of the oxidized metal alloy with an SOFC electrode. In the strip-contact model, Fig. 7 a and b, part of the current during cell operation, $I_{a}$, is assumed to flow from the contact directly and uniformly into the alloy over a contact width $\mathrm{a}+\delta$, where $\delta$ is the scale thickness, while the second part of the overall current, I(x), is assumed to flow laterally through the scale to a distance $\mathrm{x}$, where it enters the alloy over an area again of width $\delta$, leading to a local current density, $i(x)=I(x) /(\delta \ell)$, where $l$ is the contact length. The total current for the contact of width a, length $l$ and a separation distance $2 \mathrm{~L}$ between contacts, $\mathrm{I}_{\mathrm{L}}$, with

$$
\mathrm{I}_{\mathrm{L}}=\mathrm{I}_{\mathrm{a}}+\int_{\delta}^{\mathrm{L}} \mathrm{i}(\mathrm{x}) d \mathrm{x}
$$

may then be compared to that of a uniformly covering contact, $\mathrm{I}_{\text {uniform }}$, so that $\mathrm{I}_{\mathrm{L}} / \mathrm{I}_{\text {uniform }}=\mathrm{Y}(\mathrm{m}, \mathrm{k})$, with $\mathrm{m}=\mathrm{a} / \delta$ and $\mathrm{k}=\mathrm{L} / \delta$.

It is then readily shown that

$\mathrm{Y}(\mathrm{m}, \mathrm{k})=(\mathrm{m}+1) /(\mathrm{m}+\mathrm{k})+(1 /(\mathrm{m}+\mathrm{k})) \cdot \ln \mathrm{k}$, a simple geometrical factor, independent of the scale's specific resistance, $\mathrm{R}_{0}$. 
While an exact calculation can be made using finite element analysis, the present simplified model is sufficient to estimate the effects of the general contact geometry that is shown in Fig 7b. It is clear that for $L / \delta>10$ the averaged interface resistance would be significantly above that for uniform contact. The half-separation, L, between contacts could, for example be regarded as a channel width for air flow, or as the contact spacing of a porous electrode. For large values of $\mathrm{L} / \delta$ the effective interface resistance would be increased by a factor of about 10 compared to uniform contact. As a further illustration, for $L / \delta>30$, and $m=a / \delta<1$, $\mathrm{Y}(\mathrm{m}, \mathrm{k})$ is not very sensitive to $\mathrm{L} / \delta$, which leads to the conclusion that for an increasing $\delta$ at constant $\mathrm{L}$, the total ASR is approximately inversely proportional to $\sim\left[\mathrm{Y}(\mathrm{m}, \mathrm{k})^{-1}\right] \mathrm{x} \delta \mathrm{xR}_{0}$, or $10 x \delta \mathrm{x}_{0}$. This will require the oxidation scale to have a very low specific resistance if the average ASR is to remain below some acceptable level, such as $0.1 \Omega \mathrm{cm}^{2}$ after $50,000 \mathrm{hrs}$ of operation.

A similarly simplified model may be used to evaluate the case of disk-shaped contacts of radius a, with edge to edge spacing $\mathrm{L}$. Such a model leads to the approximate expression $\mathrm{Y}(\mathrm{m}, \mathrm{k})=(1 / \mathrm{k})^{2}(\mathrm{~m}+1)^{2}+(1 / \mathrm{k}) \cdot \ln (\mathrm{k} /(\mathrm{m}+1))$.

Fig. 8 compares the approximate values for $m<1$, indicating that disk-type contacts lead to more significant increases in contact resistance compared to strip contacts, as may be intuitively expected. The significance of geometrical effects on contact resistance have been considered by numerous authors, [23-27] to varying degrees of approximations. The results are generally similar.

The dependence of the ASR on temperature and time may be expressed empirically as $\operatorname{ASR}(\mathrm{t}, \mathrm{T}, \mathrm{Y})=[\mathrm{Y}(\mathrm{m}, \mathrm{k})]^{-1} \mathrm{R}_{0} \mathrm{k}_{\mathrm{p} \text { eff }} \mathrm{V}_{\mathrm{t}}$

For the coatings developed here, an oxidation of $60 \mathrm{hrs}$ at $800^{\circ} \mathrm{C}+120 \mathrm{hrs}$ at $850^{\circ} \mathrm{C}$ led to an ASR of $2.3 \times 10^{-3} \Omega \mathrm{cm}^{2}$. With $[\mathrm{Y}(\mathrm{m}, \mathrm{k})]^{-1}=10$ this would predict an ASR after 50,000 hrs at $850^{0} \mathrm{C}$ of approximately $0.5 \Omega \mathrm{cm}^{2}$.

The following strategies for reaching tolerable contact resistances can be considered:

- Introduce various doping elements to reduce $\mathrm{R}_{0}$ further

- $\quad$ Changing the contact geometry to increase $\mathrm{Y}(\mathrm{m}, \mathrm{k})$

- Changing the temperature of operation

- $\quad$ Using alloys such as Plansee or ODS alloys, with materials and processing cost penalty 
As discussed by Huang et al., [14] the benefit of reducing the temperature of operation of the fuel cell will depend on the effective activation energies of $\mathrm{k}_{\mathrm{p}}$ eff and $\mathrm{R}_{\mathrm{o}}, E_{\mathrm{a}, \mathrm{ox}}$ and $E_{\mathrm{a}, \mathrm{el}}$, with $E_{\mathrm{a}, \mathrm{ox}}$ $\propto 1 / 2 \ln \mathrm{kg}_{\mathrm{g}}$. Obviously, benefit at lower temperatures only results if $E_{\mathrm{a}, \mathrm{ox}}>E_{\mathrm{a}, \mathrm{el}}$. Activation energies for oxidation of various Fe-Cr -containing alloys have been determined by several authors. While these do not necessarily apply to the steel protected by a complex scale, it is reasonable to assume that they will generally be of comparable magnitude in the present case. Brylewski et al. [23 ] cite activation energies of about $200 \mathrm{~kJ} / \mathrm{mole}$, i.e. about $2 \mathrm{eV}$. Under these conditions, with $E_{\mathrm{a}, \mathrm{ox}}$ about $1 \mathrm{eV}$, a lowering of the temperature of operation to $700^{\circ} \mathrm{C}$ would bring the ASR down to below $0.1 \Omega \mathrm{cm}^{2}$ even if $\mathrm{Y}(\mathrm{m}, \mathrm{k}) \sim 0.1$. While further measurements, particularly for extended times at lower temperatures remain to be made, the analysis provides a plausible argument for reducing the operating temperatures of SOFCs that use protected coating on ferritic stainless steels, such as the $430 \mathrm{SS}$ used here, to $700^{\circ} \mathrm{C}$ or below.

\section{Conclusions}

1. An effective, dense and well adherent coating was produced on 430SS that has the result of significantly reducing the oxidation rate of the alloy. The coating is essentially a MnCo-O spinel, applied in powder form, and compacted to improve its green density.

2. A simplified model has been presented that allows an assessment of the effects of the contact and scale geometries.

3. For $850^{\circ} \mathrm{C}$, an ASR can be predicted of approximately $0.5 \Omega \mathrm{cm}^{2}$, after $50,000 \mathrm{hrs}$ in air, taking into account a factor of 10 penalty for unfavorable contact geometries.

4. The effect of the densified Mn-Co spinel coating is to reduce significantly $\mathrm{Cr}_{2} \mathrm{O}_{3}$ subscale formation, lower the thermal expansion mismatch, and increase the electronic conductivity of the scale.

5. The findings point to several potential remedies for achieving coatings on commercial stainless steel alloys that allow for metal interconnects with a service life of 50,000hrs or more. Considering contact geometries, such service life is unlikely to be possible above operating temperatures of about $700^{\circ} \mathrm{C}$, unless highly specialized alloys are used, with potential processing and cost penalties. 


\section{Acknowledgements}

This work was supported by the U.S. Department of Energy, National Energy Technology

Laboratory. Additional support was provided by the U.S. Department of Energy under Contract No. DE-AC03-76SF0098. 


\section{References}

1. S. de Souza, S. J. Visco and L. C. De Jonghe, Solid State Ionics, 98, 571 (1997).

2. S. de Souza, S. J.Visco and L.C.De Jonghe, Journal of Electrochem. Soc. 144, L35 (1997).

3. J-W Kim, A. V. Virkar, K-Z Fung, K. Mehta, and S. C. Singhal, J. Electrochem. Soc., 146, 69 (1999).

4. H. Ishihara, H. Matsuda and Y. Takita, J. Am. Chem. Soc., 116, 3801 (1994).

5. M. Feng and J. B. Goodenough, Eru. J. Solid State Inorg. Chem., T31, 663 (1994)

6. K. Q. Hung, R. Tichy and J. B. Goudenough, J. Am. Ceram. Soc., 81, 2565 (1998)

7. W. J. Quadakkers, H. Greiner and W. Kock, in Proc. $1^{\text {st }}$ European SOFC

Forum, U. Bossel, Ed., p. 525, Lucerne, Switzerland (1994).

8. W. J. Quadakkers, H. Greiner, M. Hansel, A. Pattanaik, A.S. Khanna, W. Mallener, Solid State Ionics, 91. 55 (1996).

9. S. Linderoth, P.V. Hendriksen and M. Mogensen, J. Mat. Sci., 31, 5077 (1996).

10. N. Q. Minh, T. Takahashi, Science and Technology of Ceramic Fuel Cells, Elsevier, Amsterdam, 1995.

11. H. Asteman, J.-E. Svensson, L.-G. Johansson, M. Norell, Oxid. Met. 52, 95(1999).

12. S.P. Jiang, J.P. Zhang, X.G. Zheng, J. Eur. Ceram. Soc., 22, 361(2002).

13. P.Y. Hou, K. Huang and W. Bakker. Proc. $6^{\text {th }}$ International Symposium on Solid Oxide Fuel Cells, Honolulu, Havaii, Oct. 17-22, 1999.

14. K. Huang, P. Hou, J. B. Goodenough, Solid State Ionics, 129, 237(2000).

15. D. G. Wickham, W. J. Croft, J. Phys. Chem.Solids 7, 351(1958).

16. S. Naka, M. Inagaki, T. Tanaka, J. Mater. Sci. 7, 441(1972).

17. Y. Larring and T. Norby, J. Electrochem. Soc, 147(9) 3251-3256 (2000).

18. S. Badwal, K. Foger, X. G. Zheng, and D. Jaffrey, US patent 5,942,349, August 24, 1999

19. L.A. Chick, L.R. Pederson, G.D. Maupin, J.L. Bates, L.E. Thomas, G.J. Exarhos, Mater. Lett. 10, 6 (1990).

20. H. Nagai, T. Fujikawa, K. Shoji, Trans. Japan Inst. Met. 24, 581(1983).

21. J.H.Zhu, Y. Zhang, A.Basu, Z.G.Lu, M. Paranthaman, D.F. Lee, and E.A. Payzant, Surface and Coatings Technology, 177-178, 65(2004).

22. D.H. Speidel and A. Muan, J. Amer Ceram. Soc., 46, 578(1963).

23. R. Holm, Electric Contacts, Chap. 1, Springer-Verlag, NY, 1967.

23. E. Gorin and H.L. Recht, in " Fuel Cells", pp 193-252, 1963. W. Mitchell, Ed., Academic Press, NY 1963.

24. J. Fleig and J. Maier, Electrochim. Acta 41(7/8), 1003-1009 (1996).

25. J. Fleig and J. Maier, Solid State Ionics, 85, 17(1996).

26. J. Fleig and J. Maier, Solid State Ionics, 86-88, 1351 (1996).

27. E. Wanzenberg, F. Tietza, D. Kek, P. Panjan, D. Stöver, Solid State Ionics, 164, 121(2003).

28. T. Brylewski, M. Nanko, T. Maruyama, K. Przybylski, Solid State Ionics, 143,131(2001). 


\section{TABLES}

Table 1.

Stainless steel composition in Weight\%

\begin{tabular}{lcccccc} 
Element & Cr & C & Ni & Mn & Si & Fe \\
\hline wt\% & 16.3 & 0.04 & 0.2 & 0.45 & 0.40 & balance
\end{tabular}

Table 2.

\begin{tabular}{|c|c|}
\hline material & $\Delta \mathrm{CTE} \times 10^{6}$ \\
\hline $\mathrm{LSM}\left(\mathrm{CTE}: 12 \times 10^{-6} \mathrm{~K}^{-1}\right)$ & 0 \\
\hline $\mathrm{MnCo}_{2} \mathrm{O}_{4}$ & -0.3 \\
\hline $\mathrm{MnCoCrO}_{4}$ & -3.1 \\
\hline $\mathrm{MnCr}_{2} \mathrm{O}_{4} ; \mathrm{Mn}_{1.5} \mathrm{Cr}_{1.5} \mathrm{O}_{4}$ & -6.7 \\
\hline $\mathrm{Cr}_{2} \mathrm{O}_{3}$ & -6.5 \\
\hline $430 \mathrm{SS}$ & -0.6 \\
\hline
\end{tabular}

Table 3.

\begin{tabular}{lccc}
\hline & $\begin{array}{c}\text { Oxidation Temp. } \\
\left({ }^{\circ} \mathrm{C}\right)\end{array}$ & $\begin{array}{c}\mathrm{k}_{\mathrm{g}} \\
\left(\mathrm{g}^{2} \mathrm{~cm}^{-4} \mathrm{~s}^{-1}\right)\end{array}$ & $\begin{array}{c}\mathrm{k}_{\mathrm{p}} \\
(\mu \mathrm{m} / \sqrt{ } \mathrm{hr})\end{array}$ \\
\hline Sample A & 850 & $1.28 \times 10^{-12}$ & $5.0 \times 10^{-1}$ \\
Sample C & 850 & $1.48 \times 10^{-14}$ & $4.4 \times 10^{-2}$ \\
\hline
\end{tabular}




\section{FIGURE CAPTIONS:}

Fig.1 Conductivities of oxides as a function of temperature, with corresponding activation energies in eV. The $\mathrm{Cr}_{2} \mathrm{O}_{3}$ value is from Ref. 20 .

Fig.2. Cross-sectional SEM images, comparing the structure of as deposited and compacted coatings after an initial heat treatment in air at $800^{\circ} \mathrm{C}$ for $60 \mathrm{hrs}$. The compacted coating has formed a dense layer, while the uncompacted one has not.

Fig.3. Weight gain of uncoated and coated samples, Type $\mathrm{A}$ and $\mathrm{C}$ respectively, during isothermal heating or cyclic oxidation at $850^{\circ} \mathrm{C}$, following an initial oxidation at $800^{\circ} \mathrm{C}$ for $60 \mathrm{hrs}$. Weight gains during the heating and cooling periods are not taken into account. The coated samples have a dramatically reduced rate of weight gain. (or delete the last two sentences).

Fig. 4 Surface, (a) Optical and (b) SEM, images of 430 SS heated at $800^{\circ} \mathrm{C} / 60 \mathrm{hr}+120 \mathrm{hrs}$ isothermally at $850^{\circ} \mathrm{C}$, after cooling to room temperature. Spalling is extensive.

Fig. 5 EDX traces (dotted lines) of scales on samples oxidized at $800^{\circ} \mathrm{C} / 60 \mathrm{hr}+120 \mathrm{hrs}$ isothermally at $850^{\circ} \mathrm{C}$;

a: oxidized uncoated steel; note the $\mathrm{Mn} / \mathrm{Cr}$ oxide scale over the chromia subscale.

b: oxidized coated steel, Type C; the Chromia sub-scale is still sub-micron. Note also the low $\mathrm{Cr}$ content of the outer scale.

Fig. 6. Electrical resistivities as a function of temperature for the various samples, with corresponding effective activation energies. The activation energies are generally less than $1 \mathrm{eV}$.

Fig 7. Simplified model geometry for assessing the effects of contact geometry on the average contact resistance. When the contact spacing get large compared to the scale thickness, the geometric penalty, proportional to $\mathrm{Y}^{-1}$, becomes rapidly large.

Fig. 8. Simplified model geometry for assessing the effects of disk contact geometry on the average contact resistance. The effects are significantly more pronounced than for strip contacts. 


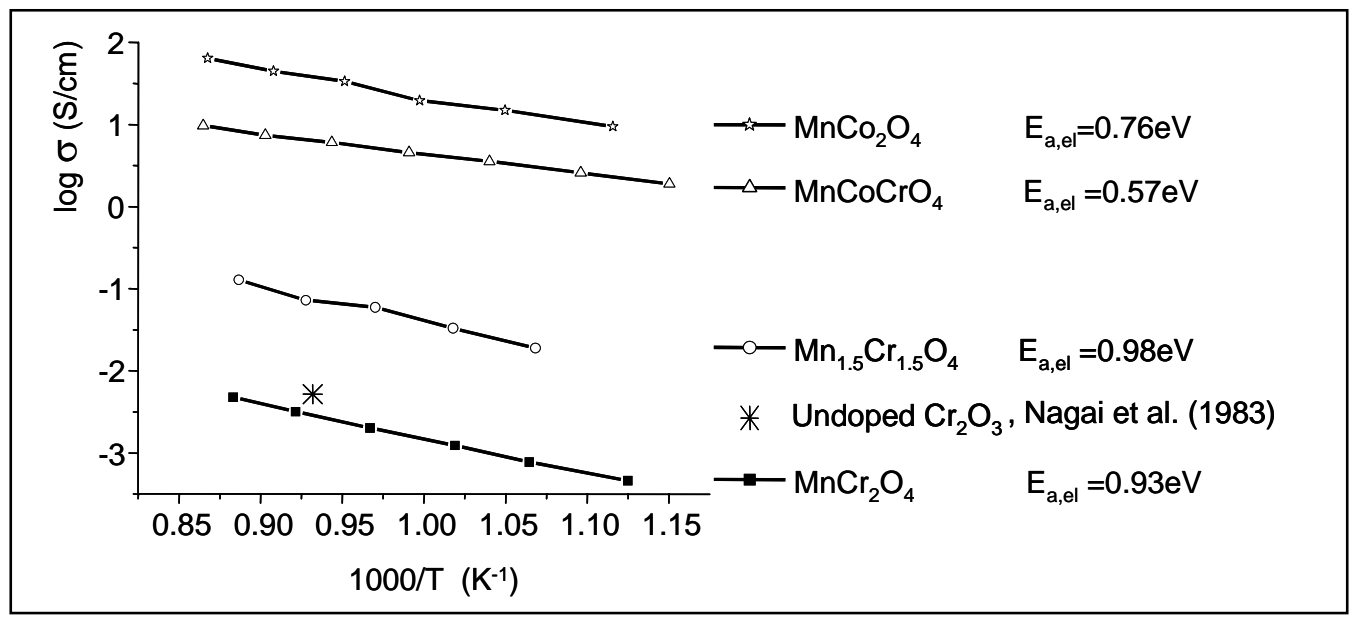

fig 1 


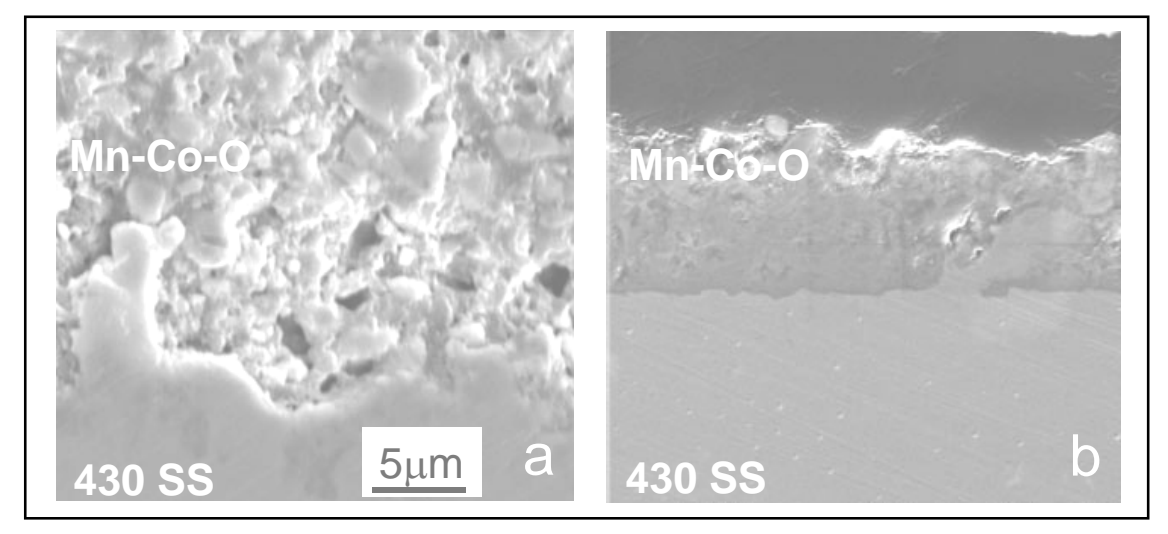

Fig 2 


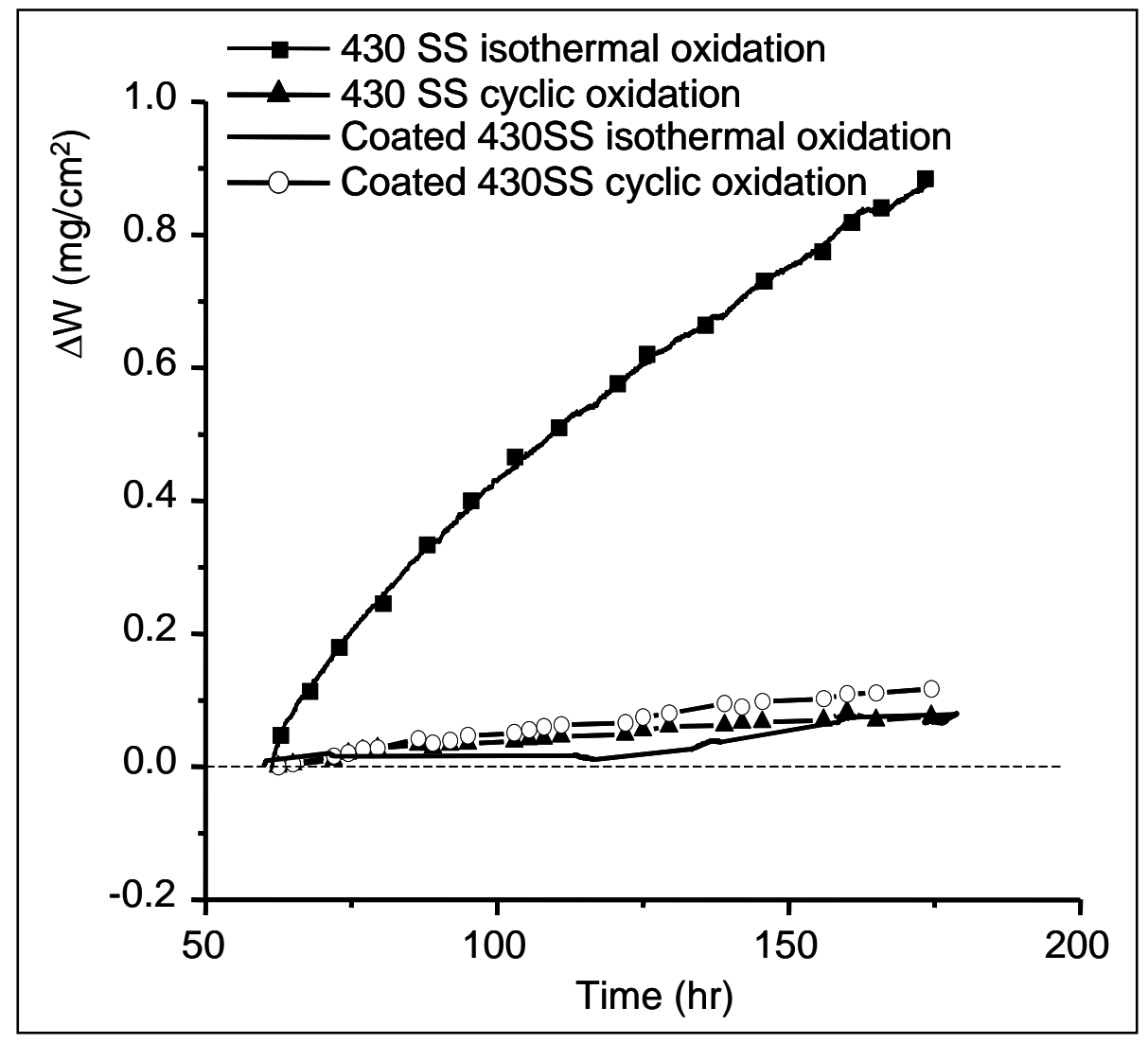

fig 3 


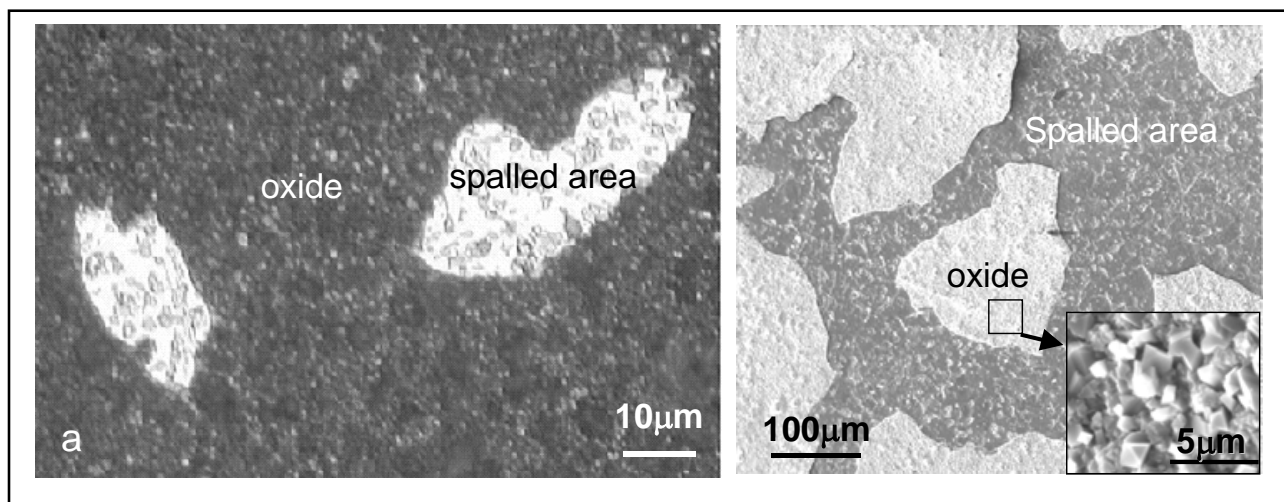

fig $4 \mathrm{a}$ and $\mathrm{b}$ 


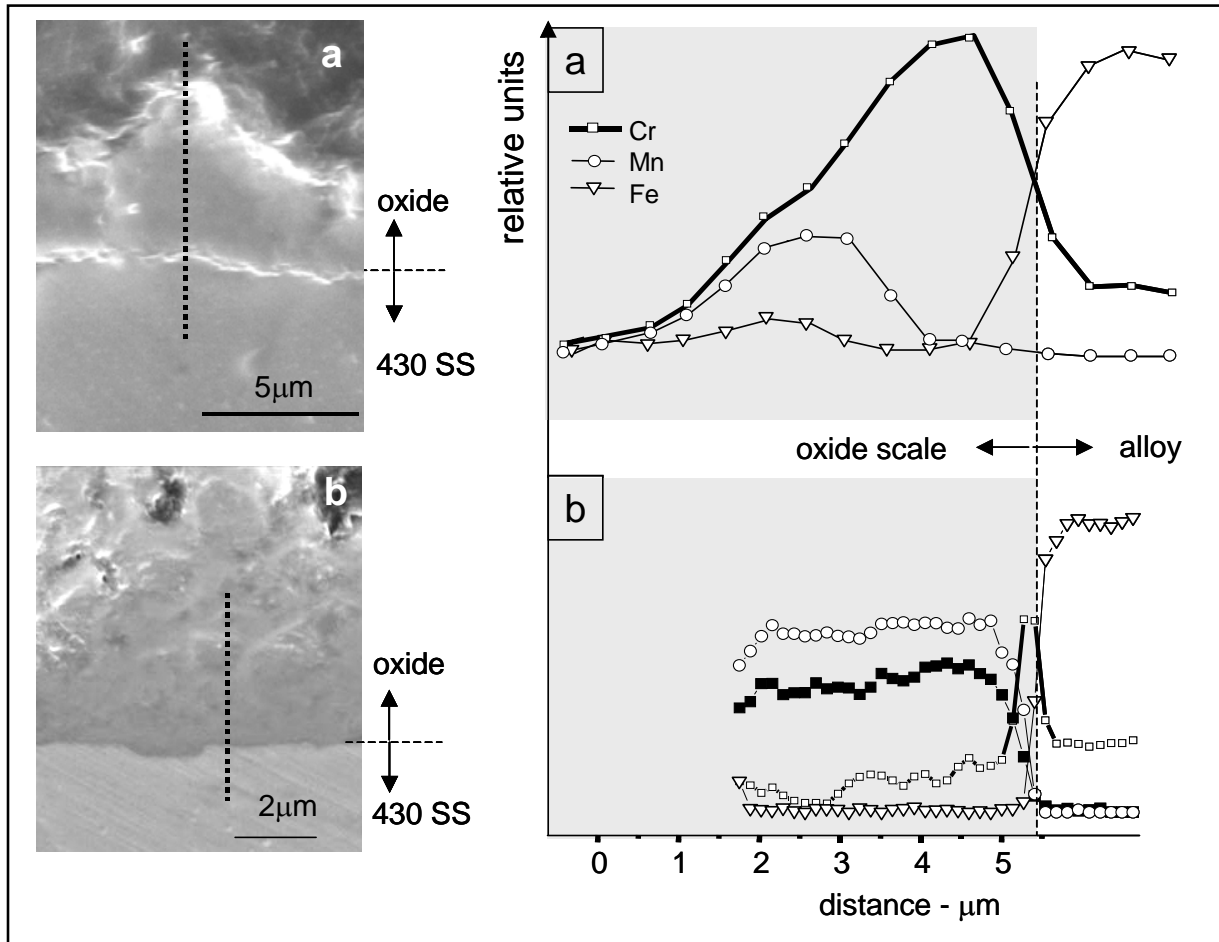

fig 5 , a,b 


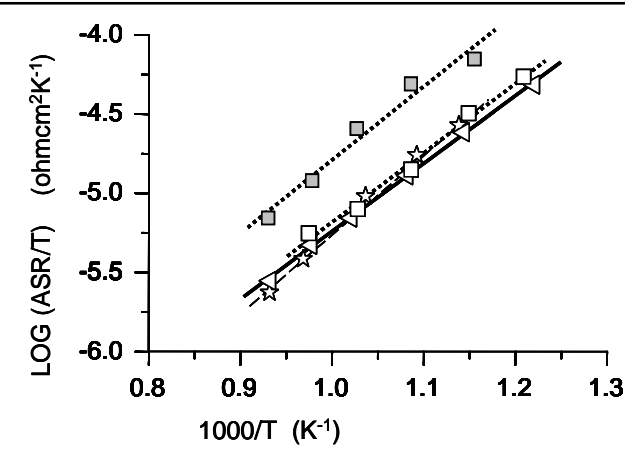

$\square$ 430SS isothermal $@ 800^{\circ} \mathrm{C} / 180 \mathrm{~h}$ in air $E_{\mathrm{a}, \mathrm{el}}=0.92 \mathrm{eV}$

$\square \quad 430 \mathrm{SS}$ isothermal @800 $\mathrm{C} / 60 \mathrm{~h}$ in air $E_{\mathrm{a}, \mathrm{el}}=0.87 \mathrm{eV}$

is Coated $430 \mathrm{SS}$ iothermal @800 $\mathrm{C} / 60 \mathrm{~h} E_{\mathrm{a}, \mathrm{el}}=0.99 \mathrm{eV}$

$\triangleleft$ Coated $430 \mathrm{SS}$ isothermal @800 $\mathrm{C} / 60 \mathrm{~h}+120 \mathrm{~h}$ cyclic $@ 850^{\circ} \mathrm{C} ; E_{a, e l}=0.85 \mathrm{eV}$

$\bigcirc$ Pure $\mathrm{MnCO}_{2} \mathrm{O}_{4} \quad E_{\mathrm{a}, \mathrm{el}}=0.76 \mathrm{eV}$

fig6 


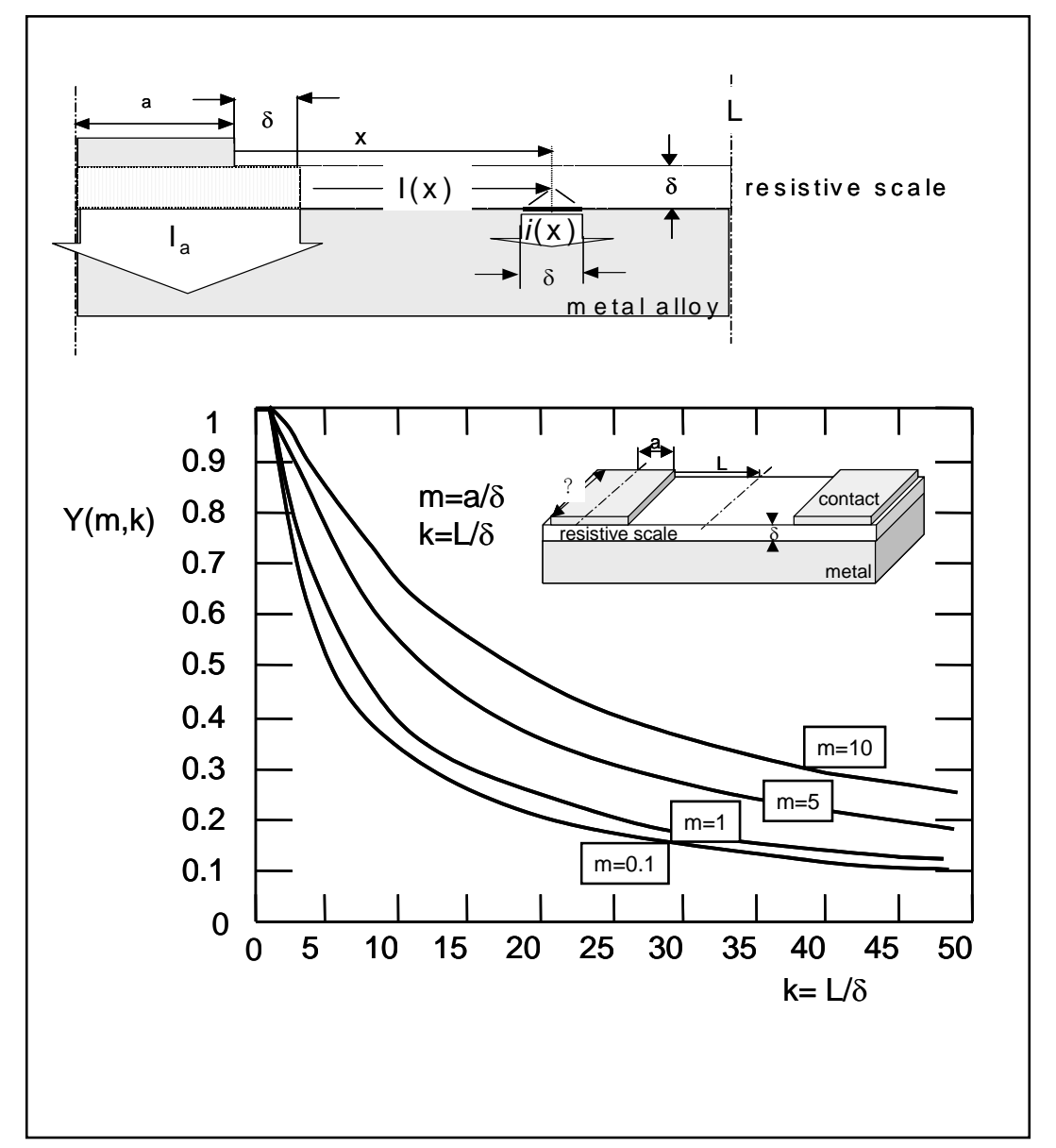

fig 7a (top),b(bottom) 


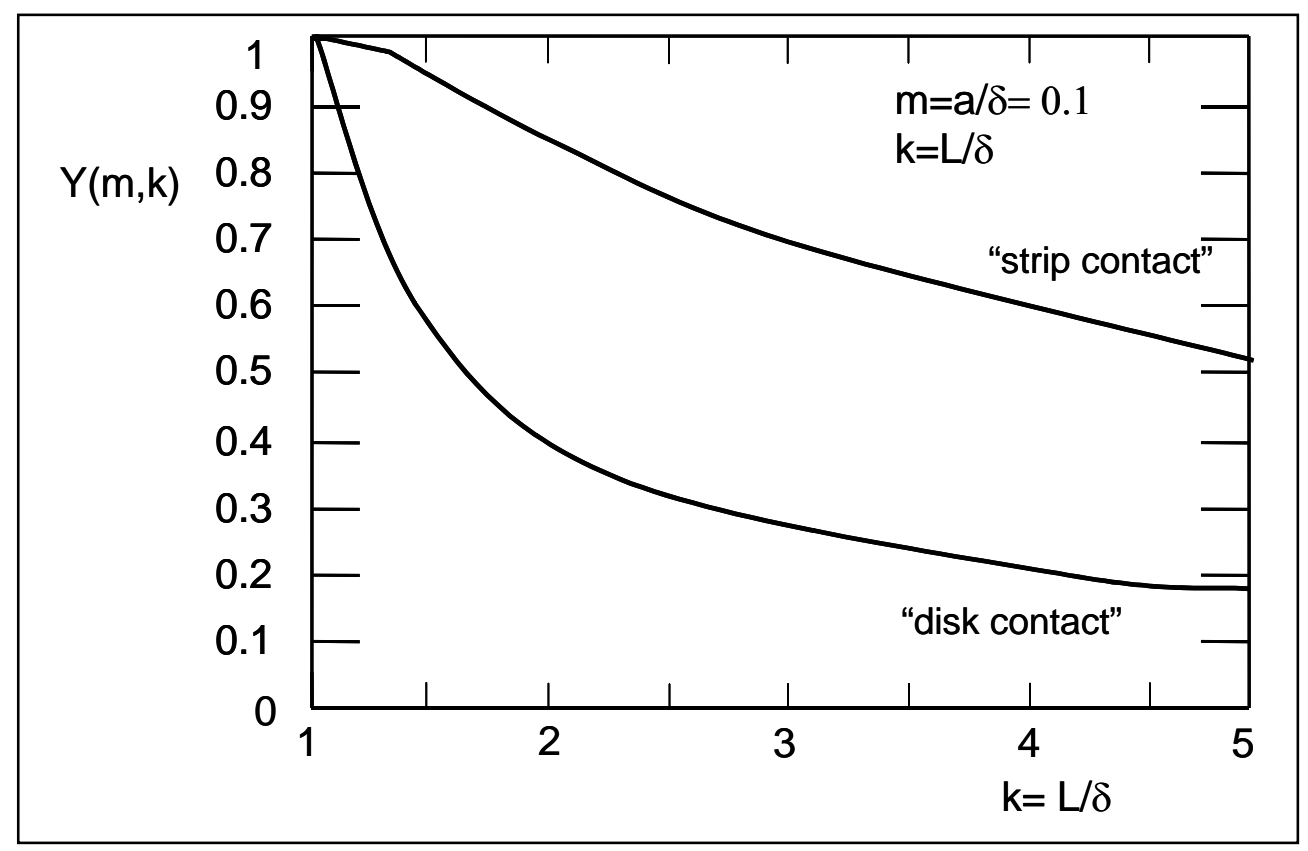

Fig 8. 